\title{
The Impact Of Just In Time On Firm Performance
}

Hwei Cheng Wang (E-mail: w2416@yahoo.com), Nova Southeastern University Ninghsin Chen (E-mail: pnhc@ mail.cju.edu.tw), Chang Jung Christian University, Taiwan Hsain-Jane Chang (E-mail:changj@tpe.boehringeringelheim.com), National Taipei University, Taiwan

\begin{abstract}
This paper explores whether different supply chain management choices such as just-in-time and non-just-in-time, which has different inventory cost has an effect on firm performance and whether or not the firm adopts the innovation approach such as JIT could increase productivity, reduce inventory and improve quality. The results indicated statistically significant differences in inventory, days to sell inventory, inventory turnover, ROA, sales, cost of goods sold, gross profit margin between JIT and non-JIT. It concluded that the adoption and implementation of innovation approach of supply chain management such as JIT did have a significant difference and improvement on firm performance.
\end{abstract}

\section{Introduction}



he purpose of this study is to examine whether the adoption and implementation of innovation approach such as just-in-time(JIT) will reduce the firm inventory and increase the efficient management of supply chain on firm performance. Just-in-time (JIT) emerged in research literature in the 1970s (Sugimore, Kusunoki, Cho and Uchikawa, 1977) and has since then been of great scholarly and managerial interest (Svensson, 2002). The significance of SCM has been of substantial importance since the early 1990s, although the approach or concept was in fact introduced in the early 1980s (Oliver and Webber, 1982). Rao and Scheraga (1988) comment that JIT is an approach to production management that can yield enormous productivity increases, inventory reductions, and quality improvements. Schonberger (1982) states that JIT is manufacturing without inventories, and the elimination of waste. Vollmann, Berry and Whybar (1988) focus on JIT as a philosophy of pursuing zero inventories, zero transactions, and zero disruptions.

Does adopting the innovation approach of supply chain such as just-in-time really increase productivity, reduce inventory, and improve quality which results in increasing the firm performance? Do the managers adopt the innovation approach of JIT that may have a significant difference in firm performance? Could JIT become the popular and innovative method instead of the traditional supply chain? To explore these issues, this study uses the inventory, day sell in inventory, inventory turnover, ROA, sales, cost of goods sold, gross profit margin as the financial indicator of firm performance to examine the JIT and non-JIT users. The basic premise investigated is that a successful choice and implementation of JIT should result in productivity increases, inventory reduction and quality improvement (Rao and Scheraga 1988). High performing JIT firms may be more likely to seek out to adopt innovative management accounting changes (Durden, Hassel and Upton, 1999).

These results should be observable in the financial statements of the company. Specifically, the balance sheet and income statement should reflect the different firm performance with JIT and non-JIT.

\section{Literature Review}

JIT is strongly associated with the marketing channel theory. The supply chain which is a part of the marketing channel from the functionalist school of marketing thought (Alderson 1957; Sheth, Gardner, and Garrett 1988) should be regarded as a single entity (Alderson, 1965), a super-organization (Stern, El-Ansary and Coughlan, 
1996) or a social system (Balderston, 1964) that consists of a number of interdependent firms that are involved in the task of the distribution of products to the ultimate consumers. Svensson (2002) states that the time and functional dependencies between companies' activities in supply chains have in the last few decades been explored in the fields of just-in-time JIT and supply chain management (SCM). JIT emerged in research literature in the 1970s (Sugimore et al., 1977) and has since then been of great scholarly and managerial interest (Svensson, 2002). The significance of SCM has been of substantial importance since the early 1990s, although the approach was in fact introduced in the early 1980s (Oliver and Webber, 1982). SCM has become an influential ingredient in today's literature.

A marketing channel and a supply chain has a vertical emphasis so that horizontal matters are not usually included (Svensson, 2001). Therefore, the theoretical perspective in this article of JIT in marketing channels is supported by and limited to channel theory (Weld, 1916; Bucklin, 1966; Svensson, 2001).

At the beginning of the twentieth century, Sheth et al. (1988) utilized economic foundations to analyze how a distribution channel could be structured more efficiently for the eventual benefit of the ultimate consumer.

In particular, the theoretical basis of this research is derived from the fact that there are dependencies between companies' business activities in supply chains (Svensson, 2002; Lambert et al., 1998; Hakansson and Snehota, 1995; Stem, 1969; Alderson, 1957, 1965; McCammon and Little, 1965; Weld, 1916).

In literature, there are many interpretations of JIT, and in order to clarify its meaning different definitions of JIT are reviewed. For example, Christopher (1992) comments on JIT that it is both a technique and a philosophy. He states that JIT is based upon the simple idea that wherever possible no activity should take place in a system until there is a demand for it. Thus no products should be made, no components ordered until there is a downstream requirement (Christopher, 1992).

Hence, JIT applies to a so-called pull strategy. Ballou (1992) defines JIT as:

A philosophy of scheduling wherein the entire supply channel is synchronized to respond to the requirements of operations or customer.

He sees JIT as a synchronised consumer driven system. Aggarwal (1985) regards JIT as an approach for providing smoother production flows and making continual improvements in processes and products. Hall (1983) states that JIT is a philosophy where all goods are to arrive exactly when they are needed neither too soon nor too late. Monden (1981) defines JIT as the idea of producing the necessary units in the necessary quantities at the necessary time. Rao and Scheraga (1988) comment that JIT is an approach to production management that can yield enormous productivity increases, inventory reductions and quality improvements. Schonberger (1982) states that JIT is manufacturing without inventories, and the elimination of waste. Vollmann et al. (1988) focus on JIT as a philosophy of pursuing zero inventories, zero transactions, and zero disruptions.

To examine the supply chain choice impacts on firm performance, there are some financial ratios to measure the firm performance. Marsh and Meredith (1998) point out that JIT success can be measured in a variety of ways including WIP levels, inventory turns, lead times, and worker productivity. This study concentrated on inventory turns and financial ratios to measure JIT success. Brown, et al. (1995) state that return on investment, return on equity, and return on assets are all closely related and widely accepted profitability measures used by internal management and external analysts to evaluate performance. ROA is used in this study because it measures a firm's ability to generate profits from assets without regard to how those assets are financed. Billesbach and Hayen (1994) use inventory turnover, inventory, inventory as a percent of total assets and sales to inventory ratio to examine the long-term impact of JIT on inventory performance measures. Inventory turnover and inventory are all relative measures of inventory management performance. Billesbach and Hayen (1994) state these ratios are not dramatically affected by the change in price levels of raw material, component parts and finished goods that impact the value of the inventory. These ratios provide an accurate measure of inventory management performance. To explores whether large retailers have shifted considerable inventory risk to their suppliers by 
implementing just-in-time (JIT) delivery systems, Gosman and Kelly (2003) use days' sales in inventory and days' purchases in accounts payable to examine both inventory and accounts payable for possible working-capital efficiencies. Therefore, to examine inventory performance this study adopted days to sell inventory, if changes in this ratio would indicate that inventory was carried on the firm's books for a longer or shorter period of time prior to its sale.

Gosman and Kelly (2002) stated gross margin percentages changes in this percentage over time could reflect adjustments in selling prices and/or purchase costs that were adapted to their study to examine changes in business relationships. To examine the managers inventory management performances, this study adopted gross profit margin.

Shmanske (2003) explores the policy of JIT inventory planning through which buffers and lot sizes are reduced and delivery frequency is increased in order to lower the amount of capital tied up inventory and points out the JIT system pioneered by Toyota let to lower inventory, lower costs, and higher quality. Durden, Hassel and Upton (1999) pointed out that cost accounting modification and performance was more strongly associated in JIT companies than in non-JIT companies. To measure the degree of accounting modification, they defined and tested the manufacturing cost item (labor, overhead) is expensed as part of cost of goods sold for the period. Therefore, this study adopted inventory and cost of goods sold to test whether adopts JIT result in lower inventory and lower costs.

The problem in JIT is not to design a supply chain theoretically, but to make it work practically (Stern et al., 1996; Svensson, 2000) the job of a channel manager is not done when that optimal channel is designed, but the manager now has to make that channel work. Because there is no guarantee that the optimally designed channel will actually operate successfully (Svensson, 2000) thought in the field of logistics, this study tests whether the managers designed and implemented aggressive supply chain management such as JIT will actually reduce inventory and cost and result in increase firm performance.

\section{Research Question}

Is there a statistically significant difference in firm performance (as expressed by the following accounting measures of firm performance: inventory, inventory turnover, ROA, days to sell inventory, sales, cost of goods sold And gross profit margin) Between those supply chain that were JIT and those that were Non-JIT?

\section{Hypothesis}

Null H1: There will not be a significant difference, at a 0.05 level of significance, in firm performance between those supply chain that were JIT and those that were Non-JIT.

H1: There will be a significant difference, at a 0.05 level of significance, in firm performance between those supply chain that were JIT and those that were Non-JIT.

\section{Research Methodology}

The first step in this study was to identify a group of JIT companies that had adopted and implemented JIT through past research and a group that had not adopted and implemented JIT through random selection.

\section{Research Design}

The set of comparisons was made between the JIT group and Non-JIT group and firm performance was examined both JIT and Non-JIT groups.

The following accounting based measures served as dependent variables for purposes of this study and were used as points of comparison: inventory, inventory turnover, days to sell inventory, ROA (return on asset), sales, cost of goods sold and GPM (gross profit margin).Sample

The data for this study was collected from COMPUSTAT database to find JIT and non-JIT companies. 
Twelve months of financial data (Jan 1, 2002 to Dec. 31, 2002) were collected from past research for 21 JIT companies and randomly collected 26 non-JIT companies from textile products. Annual reports from JIT and non-JIT were collected from Standard and Poor's Compustat. The annual reports of the JIT and non-JIT companies were analyzed.

\section{Data Analysis}

To measure firm performance, data on financial statement from JIT and non-JIT of COMPUSTAT database that were in existence in 2002 were examined and statistically analyzed their firm performance. The firm performance ratios examined included the inventory, inventory turnover, days to sell inventory, ROA-return on asset, sales, cost of good sold and gross profit margin. Table 1 shows the ratios and their methods of calculation.

The statistical package for the social sciences version 11 for Windows (SPSS) is used for the data analysis. The data were coded into Microsoft Excel and the sample checked against original returns for encoding errors. The mean ration for JIT and non-JIT are shown in Table 2.

The investigation is undertaken using a T-test for means. This involves three steps. First, it is necessary to determine whether the variances of samples are the same. The Levene test indicates whether an equal or unequal variance should be assumed. Where the Levene statistic is greater than 0.05 the equal variance T-statistic is used. Where the Levene statistic is less than 0.05 the not equal variance T-test is used. Second, the two-tailed T-test is calculated using the equal and unequal variance formula. Where the significance of a 2-tailed $\mathrm{T}$ test, using the appropriate variance equality formula, is less than 0.05 the null hypothesis is not accepted. Third, the confidence interval for those ratios shown as significant with the two-tailed test is considered. Where the $95 \%$ confidence interval contains a zero value the null hypothesis cannot be accepted. A summary of the analysis is presented in Table 3.

The financial results for JIT and non-JIT companies were collected from COMPUSTAT in 2002. The mean of each sub group was then calculated on the variables of inventory, inventory turnover, days to sell in inventory, ROA-Return on Asset, sales, cost of goods sold and gross profit margin. Then, a T-test of significance with a confidence level of $95 \%$ was performed on all variables in order to test the null hypothesis.

\section{Result And Finding}

As stated in the null format, hypothesis posits that there will not be a significant difference, at a 0.05 level of significance, in profitability between those supply chain management that were JIT and those that were non-JIT companies. Results of the t-test conducted on the means differences between the JIT and non-JIT are significantly differences for each of the 5 ratios examined. The results indicated that JIT has higher firm performance ratios than non-JIT companies.

Results of the t-tests conducted on the variables revealed that differences in the mean averages of inventory, ROA, sales, cost of goods sold and GPM variables were statistically significant at the .05 level $(\mathrm{t}=2.113$, $\mathrm{t}=3.362, \mathrm{t}=2.262, \mathrm{t}=1.893, \mathrm{t}=4.919$ respectively) difference for those supply chain management that were JIT companies and those were non-JIT companies. The results rejected the null hypothesis and concluded that there was a significant difference, at a 0.05 level of significance, in firm performance between supply chain that those were JIT companies and those that were non-JIT companies.

The results found that the mean ROA and GPM $(6.2882$, 44.8002) ratios in JIT group are higher than non-JIT group $(-15.5773,21.2097)$. This results show that non-JIT group is less firm performance than non-JIT group due to less sales, GPM and ROA. For the inventory turnover, JIT group is 5.42 higher than non-JIT only which is 5.09. It found that JIT group has better inventory management on firm performance.

\section{Summary And Conclusions}

The results of this study indicated that there are significant differences between JIT and non-JIT users. The 
findings suggested that the firms, which adopted the innovation approach of supply chain management such as JIT resulted to reduce inventory turnover and cost of goods sold; increase sales, GPM and ROA. JIT could become a popular innovation method instead of traditional supply chain management. The results also indicated that there are some ratios that do not show a significant difference across JIT and non-JIT. These ratios are days to sell inventory and inventory turnover, they indicated that both JIT and non-JIT did manage inventories well as compared to the Analyst requirement.

A number of limitations in this study must be noted. First, the sample size was relatively small and not cross-sectional in nature, since the sample was restricted to manufacturing JIT industries. Thus, the generalization of the research results is somewhat limited. The second limitation is that only financial ratio variables were included. There may be other important key quantitative variables such as market value, stock return, size and qualitative variables such as leadership, type of ownership which organization theory reports the importance of these variables. The third limitation is that the possibility of bias in reported industry averages the firm performance ratios due to the nature of the raw data collection process. Finally, this study examined only the differences in the means of ratios. A better understanding of the distributional characteristics of ratios in JIT and non-JIT is also needed.

\section{Suggestions For Future Research}

This study explores whether or not the firms adopt just in time or new innovation techniques method will results on costs reduction and have better firm performance, the future research may explore whether other new innovation techniques method such as activity-based costing will also help the firms reduce costs.

\section{References}

1. Aggarwal, R.L. (1985). MRP, JIT, OPT, FMS?. Harvard Business Review, 85(5), 8-16.

2. Alderson, W. (1957). Marketing Behavior and Executive Action: A Functionalist Approach to Marketing Theory. Richard D. Irwin, Homewood, IL.

3. Alderson, W. (1965). Dynamic Marketing Behavior: A Functionalist Theory of Marketing, Richard D. Irwin,_Homewood, IL.

4. Brown, R. M, Gatian, A. W. \& Hicks, J. O. (1995). Strategic information systems and financial performance. Journal of Management Information Systems, 11(4), 215-249.

5. Bucklin, L.P. (1966). A Theory of Distribution Channel Structure. University of

6. California, Berkeley, CA.

7. $\quad$ Christopher, M. (1992). Logistics: The Strategic Issues. Chapman \& Hall, London.

8. Durden, C. H., Hassel, L. G. and Upton, D. R. (1999). Cost accounting and performance measurement in a just-in-time production environment. Asia pacific journal of management, 16(1), 111-121.

9. Gosman, M. \& Kelly, T. (2003). Working-capital efficiencies resulting from large retailers' power. Commercial Lending Review, 18(2), 25-32.

10. Gosman, M. L. and Kelly, T. (2002). Big customers and their supplies: A case examining changes in business relationships and their financial effects. Issues in Accounting Education, 17(1), 41-57.

11. Hakansson, fl. and Snehota, I. (1995). Developing Relationships in Business Networks. Routledge, London.

12. Hall, R.W. (1983). Zero Inventories. Dow JonesIrwin, Homewood, IL.

13. Lambert, D.M., Cooper, M.C. and Pagh, JD. (1998).Supply chain management: implementation issues and research opportunities. International journal of Logistics Management, 9(2), 1-19.

14. Marsh, R. F. and Meredith, J. R. (1998). Changes in performance measures on the factory floor. Production_and Inventory Management, 39(1), 36-41.

15. McCammon, B.C. and Little, RX (1965). Marketing channels: analytical systems and approaches. in Schwartz, G. (Ed.), Science in Marketing, John Wiley \& Sons, New York, NY.

16. Monden, Y. (1981a). Adaptable Kanban system helps Toyota adapt to demand changes and reduce inventory. Industrial Engineering, 13( 8), 42-51

17. Monden, Y. (1981b). What makes the Toyota production system really tick?. Industrial Engineering, 5(1), 
20-30.

18. Oliver, RK. and Webber, M.D. (1982). Supply-chain management logistics catches up with strategy. in Christopher, M. (Ed.) (1992). Logistics: The Strategic Issues, Chapman \& Hall, London, 63-75.

19. Rao, A. and Scheraga, D. (1988). Moving from manufacturing resource planning to just-intime manufacturing. Production and Inventory Management Journal, 29(1), 44-49.

20. Schonberger, R.J. (1982). Japanese Manufacturing Techniques: Nine Hidden Lessons in Simplicity. The Free Press, New York, NY.

21. Shmanske, S. (2003). JIT and the complementarity of buffers and lot size. American Business Review, 21(1), 100-107.

22. Stern, L.W. (1969). Distribution channels: a social system approach to the study of marketing. in Stevens, W.D. (Ed.), Social Responsibility of Marketing, American Marketing Association, Chicago, IL.

23. Stern, L.W., El-Ansary, A.I. and Coughlan, A.T. (1996). Marketing Channels, Prentice-Hall International, Upper Saddle River, NJ.

24. Sugimore, Y., Kusunoki, K., Cho, F. and Uchikawa, S. (1977). Toyota production system and kanban system: materialization of just-in-time and respect-for-human system. International Journal of Production Research, 15(6), 553-564.

25. Svensson, G. (2000). A conceptual framework for the analysis of vulnerability in supply chains. International Journal of Physical Distribution \& Logistics Management, 30(9), 731.

26. Svensson, G. (2001). Just-in-time: The reincarnation of past theory and practice. Management Decision. 39(10). 866-880.

27. Svensson, G. (2002). The measurement and evaluation of mutual dependence in specific dyadic business relationships. The Journal of Business \& Industrial Marketing , 17(1), 56-73.

28. Vollmann, T.E., Berry, W.L. and Whybark, D.C. (1988). Manufacturing Planning and Control Systems, Richard D. Irwin, Homewood, IL.

29. Weld, L.D.H. (1916). The Marketing of Farm Products, The Macmillan Company, New York, NY.

Table 1: Ratios And Their Calculation

Variable

Variable Name and Method of Calculation

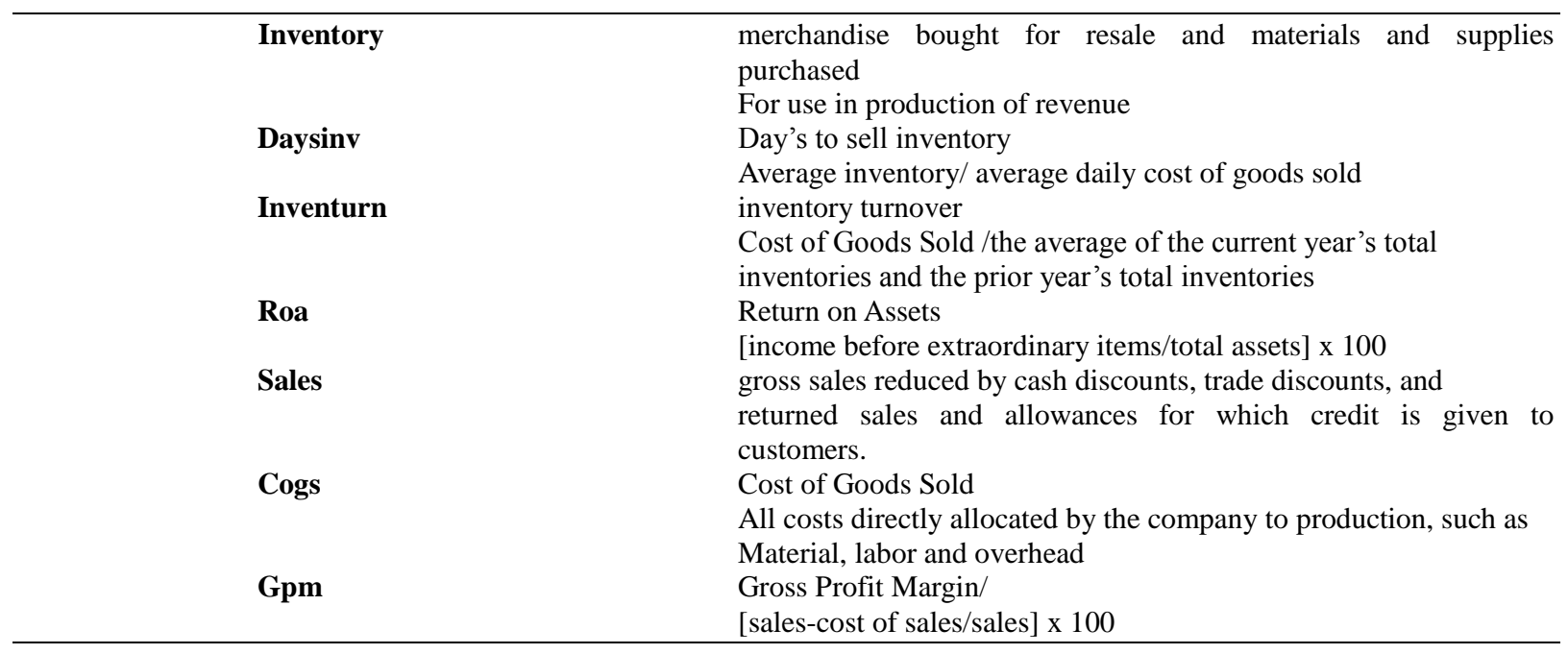


Table 2 Group Statistics

\begin{tabular}{|l|c|c|c|c|c|}
\hline & JIT & $\mathbf{N}$ & Mean & Std. Deviation & $\begin{array}{c}\text { Std. Error } \\
\text { Mean }\end{array}$ \\
\hline INVENTOR & JIT & 21 & 2484.4359 & 5292.53706 & 1154.92627 \\
& NONJIT & 26 & 44.4262 & 46.87951 & 9.19383 \\
DAYSINV & JIT & 21 & 89.3802 & 40.68772 & 8.87879 \\
& NONJIT & 25 & 78.3009 & 27.44174 & 5.48835 \\
INVTURN & JIT & 21 & 5.42 & 4.164 & .909 \\
& NONJIT & 26 & 5.09 & 2.649 & .520 \\
ROA & JIT & 21 & 6.2882 & 6.52919 & 1.42479 \\
& NONJIT & 26 & -15.5773 & 32.35963 & 6.34625 \\
SALES & JIT & 21 & 20107.2644 & 40155.03055 & 8762.54605 \\
& NONJIT & 26 & 282.2045 & 293.60512 & 57.58070 \\
COS & JIT & 21 & 12875.6293 & 30604.04580 & 6678.35031 \\
& NONJIT & 26 & 230.6337 & 245.35354 & 48.11779 \\
GPM & JIT & 21 & 44.8002 & 14.50205 & 3.16461 \\
& NONJIT & 26 & 21.2097 & 18.37582 & 3.60380 \\
\hline
\end{tabular}


Table 3 -Independent Samples Test

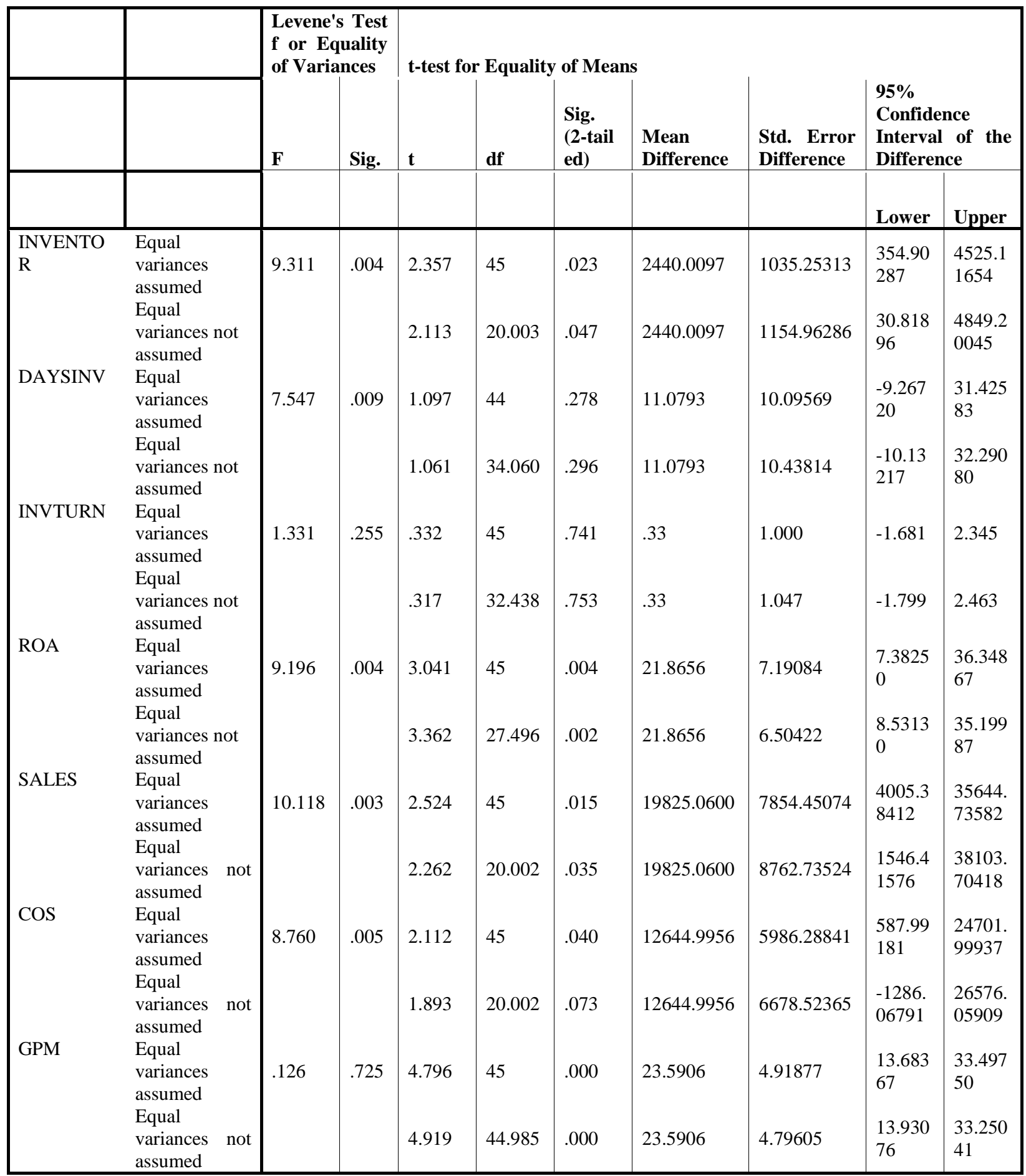

